\title{
The Role of the Reflective Activity of Students in Individual Educational Trajectory
}

\author{
Rezeda M. Khusainova ${ }^{1}$, Svetlana E. Chirkina ${ }^{1}$ \& Rashida G. Gabdrakhmanova ${ }^{1}$ \\ ${ }^{1}$ Kazan (Volga region) Federal University, Kazan, Russia \\ Correspondence: Rezeda M. Khusainova, Kazan Federal University, Kremlyovskaya Street 18, Kazan, 420008, \\ Russia. E-mail: rezedakhusainova@mail.ru
}

Received: January 19, 2014 Accepted: February 22, $2015 \quad$ Online Published: March 25, 2015

doi:10.5539/res.v7n5p146 URL: http://dx.doi.org/10.5539/res.v7n5p146

\begin{abstract}
The current stage of higher education development implies a qualitative change in approaches to the definition of its content, as well as the methods and forms of determining educational outcomes of educational and cognitive activity of students. The ability to reflect is included in the number of compulsory academic abilities of high school for students to master. Despite the long-standing discussion of reflection categories in the philosophical, psychological and pedagogical literature, the shortage of scientific and practical knowledge of the methods and techniques of diagnosing and fixing the reflection of the students is recorded. The article presents a technique that is based on the reflective card, which is aimed at a comprehensive evaluation of educational outcomes on account of bringing to the evaluation of all participants in the educational process, to assess the skills of reflection (self-evaluation) formation of the results of students' educational activities, which ultimately help to determine the degree of the discipline mastery. Results of the article are of great value for the organizers of professional training of educational psychologists, academics, as well as valuable in developing recommendations regarding policy-making in the field of supplementary education in "Practical Psychology in Education."
\end{abstract}

Keywords: method, reflection, reflective card, student, individual educational trajectory

\section{Introduction}

\subsection{Actualizing the Problem}

Relevance of the research subject is conditioned by the fact that the present stage of higher education development implies a qualitative change in approaches to the definition of its content, as well as the methods and forms of determining educational outcomes of educational and cognitive activity of students (Shaidullinaet al., 2015; Masalimova \& Nigmatov, 2015; Levina et al., 2015; Sibgatova et al., 2015; Mokeyeva et al., 2015). This is due to the formation of a new paradigm of higher education, which is based on the idea of testability of educational results, transparency of methods and forms of testing. A special aspect of the studied problem acquire the fact, that the skill to reflect is included in the number of academic abilities of high school required for students to master.

\subsection{Explore Importance of the Problem}

At the same time, despite the long-standing discussion of reflection categories in the philosophical, psychological and pedagogical literature, the shortage of scientific and practical knowledge of the methods and techniques of diagnosing and fixing the reflection of the students of higher education is recorded. In psychology, reflection is understood as a process of self-discovery of internal mental states and acts as the fundamental mechanism of mental introspection, reflection and critical evaluation of the individual's own actions (Biktagirova \& Valeeva, 2013). Possession of reflection skills becomes especially important when it comes to the students of psychological and pedagogical fields of study at the university (Biktagirova \& Valeeva, 2014).

Educational activity is reflective in nature, but reflection as a pedagogical category is poorly studied. Bizyaeva (2004) explains the pedagogical reflection as a complex psychological phenomenon, which manifests itself in the ability of teachers to enter the active research position in relation to their activities and to themselves as its subject to critically analyze, interpret and evaluate its effectiveness for the development of the student's personality. Representatives of the pedagogical direction, such as Botsmanova (2006), Zak (1978), Zakharova 
(1993, 2006), Polivanova (2007), Bessonova (2000), Vulfov and Harkin (1995), Pyankova (2009, 2010), Romanova and Konstantinov (2012), Gabdilkhakov and Kalimullin (2014), Savenkova (2005) understand reflection as a tool for the organization of educational activities. Without understanding their teaching methods, mechanisms of learning and mental activity, students will not be able to assign the knowledge that they have obtained. Reflection helps students to formulate the results obtained, to predetermine the purpose of further work, to correct their educational path. Feofanov (on Pyankova, 2009) believes that the study of students' reflection is necessary to manage the learning process itself. Because, getting information from the learners about how they realize, what they learn and what they do not understand, the teacher can correct his educational activities States of system-activity approach made the methodological basis of the study of reflection (Rubinstein, Lomov, Shadrikov, \& Karpov). Davydov, Kulyutkin and Semenov (2009, 2011), Stepanov were researching reflection in the context of the problems of thinking psychology. Karpov (2003) pointed out the lack of theoretical and experimental study of reflection in learning activity especially in the problem of the genesis of reflection and the content of education.

\section{Methodological Framework}

The study of the curriculum of basic education programs in high school, allows to observe that significantly more hours are allocated on independent work of students than on classroom work. In such circumstances, the responsibility of the student and the teacher for educational outcomes increases. It is necessary for the student to have a high level of reflection (in this case, self-esteem) in order to increase his responsibility for learning outcomes. Accordingly, the most important educational objective is to design specific basic operations, problematic situations in their functioning and organization of reflection. The tasks that are offered by the teacher to the student, should assume the student's reflection. And the teacher should be able to make measurements and determine the changes and the dynamics of student's reflection.

Reflection acts in this case as an indicator of subjectivity and allows the person to regulate his own activity, to influence the system of norms and standards, to govern the educational and practical activities. Occupying a reflective position, students analyze, think critically about their activities, compare its objectives and outcomes, seek to understand its features, advantages and disadvantages. Reflection is understood as a person's ability to realize his own activities, to see their progress and errors. In this case, reflection is aimed at finding the causes of failures and difficulties, during which we realize that the used means are not up to the task, as a result, a critical attitude to one's own means is being formed, and then to the conditions of the problem a wider range of resources is being applied, conjectures and hypotheses are being put forward, intuitive solution of the problem (on an unconscious level) occurs (i.e., there is a decision in principle), and then the rationale and implementation of solutions take place. Retrospective reflection is used to analyze the activities already carried out, the events that occurred in the past. Thus, reflection affects the prerequisites, motives, conditions, stages and results of operations or its individual stages already in the past. Educational reflection implies an ability to analyze the results of its operations, delineate its own activities in addressing the learning task, to correrc their own actions. In other words, "the ability to think how I think, to know what I know, and to know how I know." Educational reflection in professional activities has the potential development, which under certain conditions allows to raise it to a new level. The profession of a teacher or a practical psychologist, which belongs to the profession type "man-man", is qualitatively different to the availability of competence in interacting with people. In this regard, the formation of reflection in the system of psycho-pedagogical education is extremely important.

So, reflection is built around the explanation of the so-called points of support-existing knowledge and skills that allow to achieve success and growth points - deficits and difficulties that hinder the achievement of planned results.

Reflective understanding of the points of support and points of growth, allows:

- To fix features of the motion in the activities concerning the expected results, as well as significant changes, happening in the subject of activity;

- Through the understanding of obtained practice to translate it into experience, which can be used in the future;

- On the basis of the above mentioned, to draw conclusions, and make timely adjustments to the subsequent activity, making it more efficient.

In order to organize the reflection activity we can use such forms and methods of work as:

- Group and individual work;

- Discussion in seminars; 
- Written work (answers to questions by the method of incomplete sentences, psychological testing, etc.).

Accordingly, the reflection is the basis of various activities of students in the study of their disciplines. This may be listening to lectures, reading texts, analysis of the literature, writing essays, summaries, but the ways to integrate reflective mechanisms are purely individual. According to Tyukov (1995), reflective mechanism consists of six steps:

- Reflective way out—is performed when other means and methods are not enough to know oneself and another person.

- Intentionality — focus on an object of reflection, highlighting it from other objects.

- Primary categorization - the choice of primary means, with the help of which the reflection is carried out.

- Construction of the system of reflective means - selected primary means are combined in a certain system, which enables a more focused and reasonable verification of the reflective analysis.

- Schematization of the reflective content is performed by the use of different symbolic means: images, diagrams, symbols, and language constructions.

- Objectification of the reflective description - evaluation and discussion of the results. In that case, if the result is not satisfied, the process of reflection starts again from the very beginning.

\section{Discussions}

We have been tasked to find out what teaching tools will help to "launch" the reflective mechanism. In this case, they must be easy to use and by the teacher and the student to determine the level of awareness in activity movement with respect to the expected learning outcomes.

Diagnostic means of studying of the regulatory component of reflection (self-esteem and self-control of the ways of doing business) are under development. According to Makarova (2005) oral and written survey of students allows to record, what ways of reflection the learner possesses or does not possess, the ability to assess and control themselves-The level of self-planning control and the adequacy and differentiation of self-assessment.

Malskaya and Sidelnikova suggest to use diagnostic opportunities of the survey with the elements of the clinical interview for the study of reflection in pupils' learning activity.

Reflective activity in terms of personal development of students in a generalized form must be associated with their realization of the training activity, the ability to analyze educational motives, needs, actions and behavior in general. Accordingly, it will be characterized by such features as purposefulness, objectivity, meaningfulness. Thus, for the organization of a reflective activity of students the teacher must provide the student with an opportunity to choose individual educational trajectory considering his features and capabilities, contribute to the formation of the ability to fix the successes and difficulties, their causes, and develop the ability to adequately treat emerging problems and seek their solutions.

\section{Results}

The following conditions will play an important role in the structure of students' reflective activities: implementation of educational tasks, including reflection and aimed at introspection of educational activities; the use of innovative teaching methods of control such as portfolio, project method, etc; students' fixing of the educational advancement (self-development) after each training unit, whether lectures, practical training, or study of a subject discipline in general (filling in special charts, scheduling, the introduction of symbols) and their analysis; conducting special training to develop the skills of reflection. Such course as part of our experiment is the reflective elective course "Climbing to the profession." In this course discussion forums are organized, where students have an opportunity to defend their projects, portfolios, analyze the results of their professional development, as in the theoretical training, and during continuous psychological and pedagogical practice, which is called "Reflective dive into the profession".

Beginning the realization of a discipline program, we propose to determine originally the level of students' personal reflection, the results of which will help to plan the future work with students. We propose to use "Methods of determining the level of reflectivity" by Karpov and Ponomareva. This is a psychometric method of diagnosis of individual measures of the property development of reflectivity.

The second stage of evaluating skills formation of reflection, we propose to use a reflective card for determining the level of training (corresponding to the professional requirements) reflection. According to the dictionary of a practical psychologist (Golovin, 1998), reflection is not just knowledge or understanding of the subject himself, but also figuring out how others know and understand "the reflective person", his personality traits, emotional 
reactions and cognitive (related with knowledge) impressions. Thus, the reflective card of evaluating the formation of reflection skills (self-evaluation) of the results of students' educational activity is based on a technique of "360 degrees", which is aimed at a comprehensive evaluation of forming educational outcomes on account of bringing to the evaluation of all participants in the educational process, to determine the educational outcomes. The evaluation of the level of reflection's skills formation of the results of students' educational activities carry out the discipline teacher, classmate, supervisor of teaching practice, the expert. The prospective employer can be as an expert.

Reflective card consists of tables and charts (Table 1,2), compiled in the program Microsoft Excel. The obtained results are automatically displayed in the diagram (Fig. 1). In this case, the student (teacher, classmate, expert, etc.) fixes to what extent the allocated in the form of a clear and predetermined criteria, educational outcomes in a given scale (0 to 10) are formulated. Careful analysis is carried out when the points put by different participants in the survey coincide.

Table 1. Reflective card

\begin{tabular}{|c|c|c|c|c|c|}
\hline \multirow{2}{*}{$\begin{array}{l}\text { on } 00.00 .20 \\
\text { Criteria of educational } \\
\text { outcomes formation }\end{array}$} & \multicolumn{5}{|c|}{ Name of a student } \\
\hline & $\begin{array}{l}\text { Self- } \\
\text { assessment }\end{array}$ & $\begin{array}{l}\text { Mutual } \\
\text { evaluation }\end{array}$ & $\begin{array}{l}\text { Expert } \\
\text { assessment }\end{array}$ & $\begin{array}{l}\text { Teacher } \\
\text { assessment }\end{array}$ & $\begin{array}{lr}\text { Average of skills } & \\
\text { formation } & \text { of } \\
\text { self-assessment (+, -) }\end{array}$ \\
\hline $1 * * *$ & $\mathrm{xx}$ & $\mathrm{xx}$ & $\mathrm{xx}$ & $\mathrm{xx}$ & \\
\hline $2 * * *$ & $\mathrm{xx}$ & $\mathrm{xx}$ & $\mathrm{xx}$ & $\mathrm{xx}$ & \\
\hline $3 * * *$ & $\mathrm{xx}$ & $\mathrm{xx}$ & $\mathrm{xx}$ & $\mathrm{xx}$ & \\
\hline $4 * * *$ & $\mathrm{xx}$ & $\mathrm{xx}$ & $\mathrm{xx}$ & $\mathrm{xx}$ & \\
\hline $5 * * *$ & $\mathrm{xx}$ & $\mathrm{xx}$ & $\mathrm{xx}$ & $\mathrm{xx}$ & \\
\hline $6^{* * *}$ & $x x$ & $\mathrm{xx}$ & $\mathrm{xx}$ & $x x$ & \\
\hline
\end{tabular}

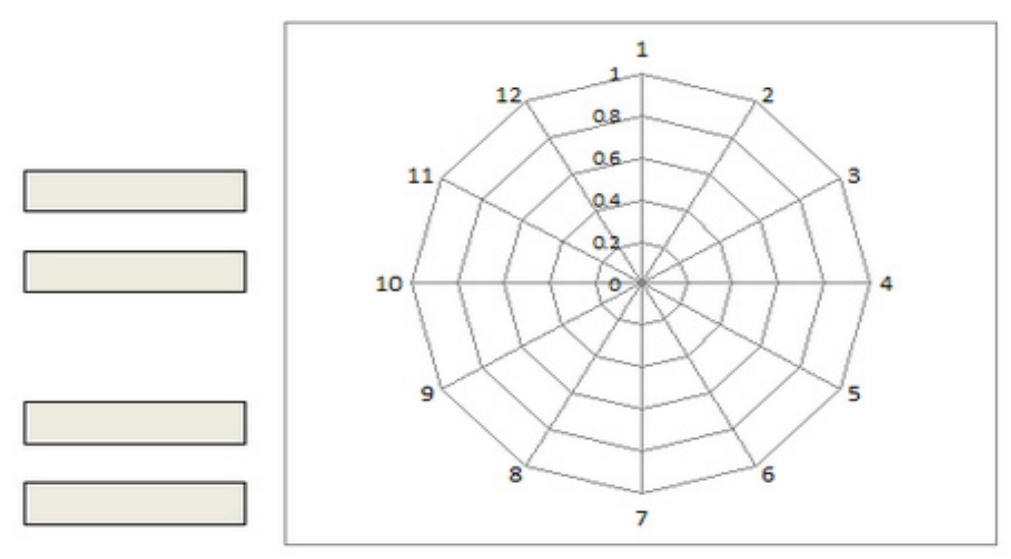

Figure 1. Diadram 1 reflective card

\section{Explanatory note}

Name - the student - in the nominative case

instead of XX introduce the value assessment on a 10-point scale (number only)

Request:

1) The remaining cells do not touch

2) RC (Reflective card) is filled in for each student individually 
Table 2. Reflective card

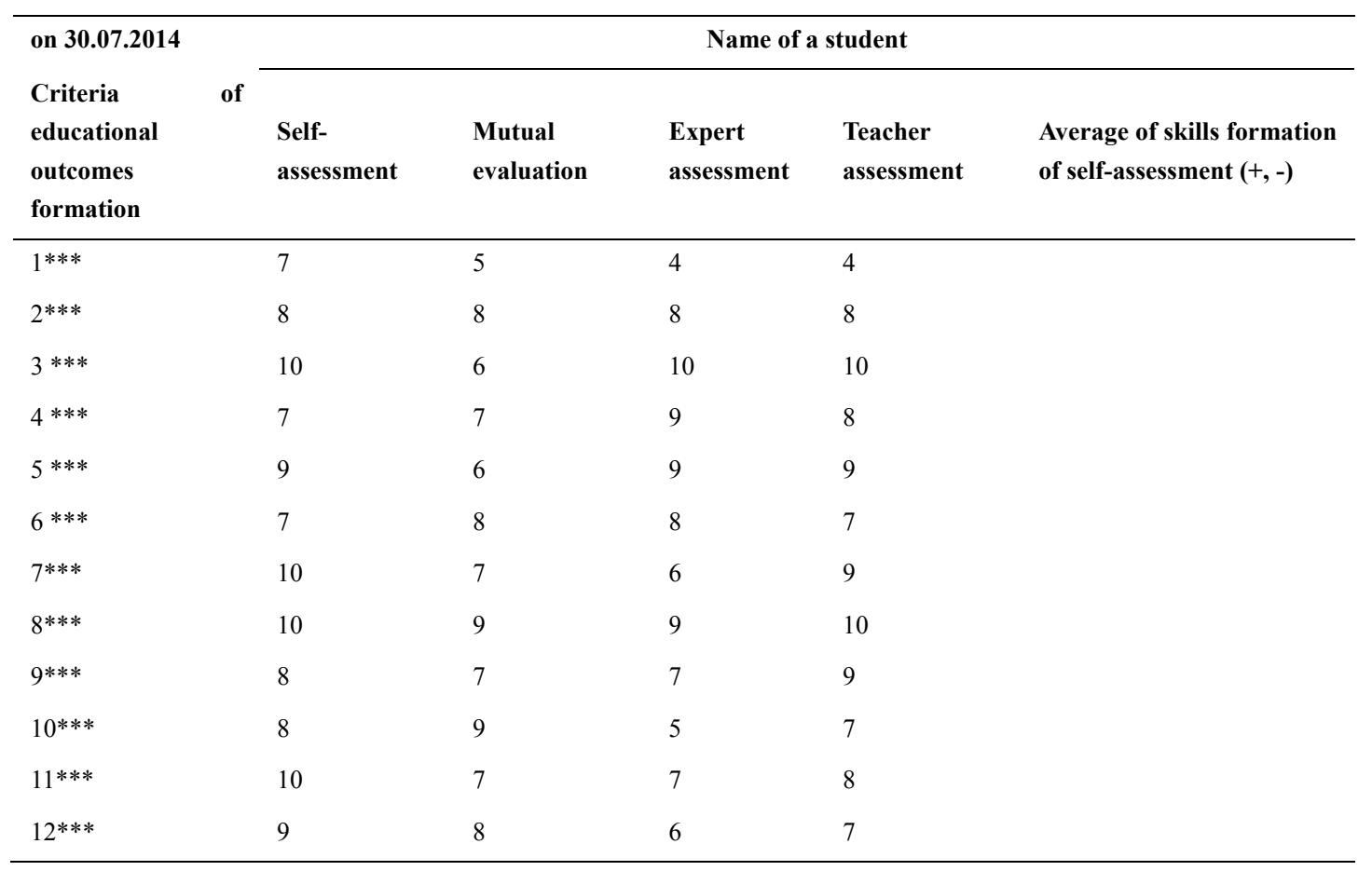

The teacher thinks over what educational outcomes (column "Criteria of educational outcomes formation") in this case will be announced to monitor their level of formation. After that, the table is given to fill in to the survey participants. Points of completed table are transferred to the table Microsoft Excel, which helps to build the diagram (Fig. 2)

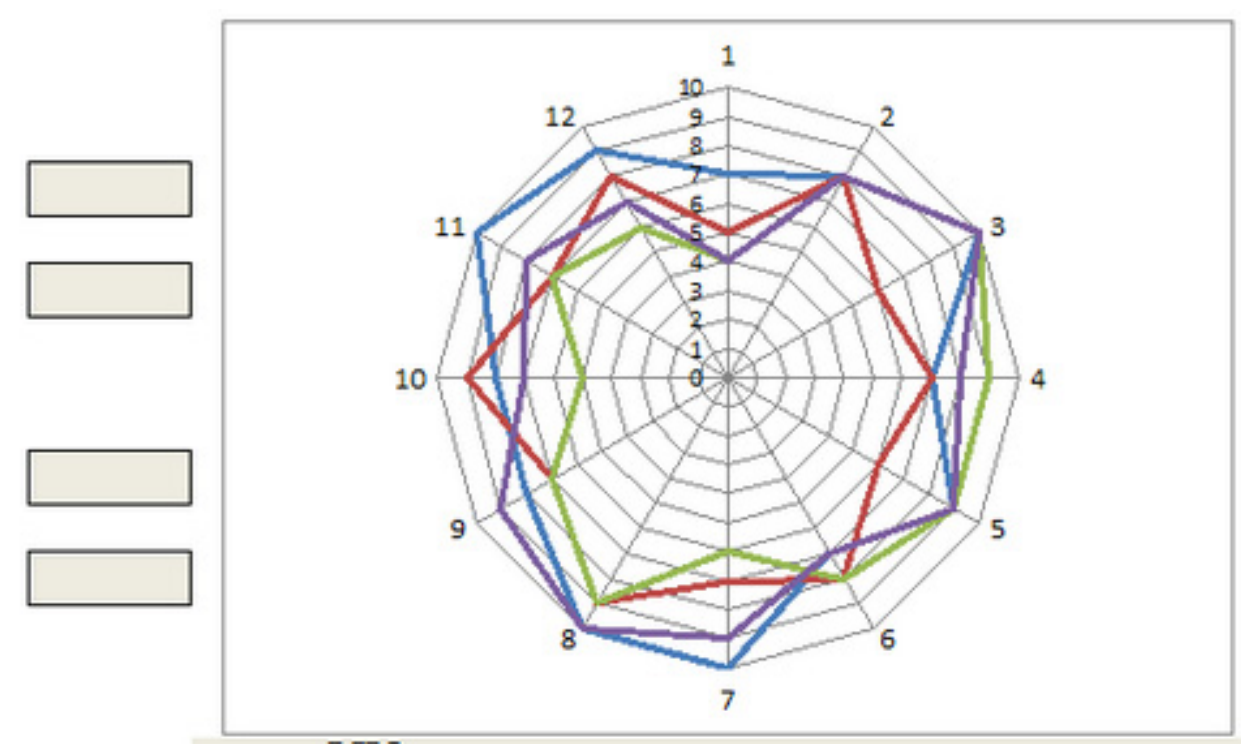

Figure 2. Diagram 2 reflective card

\section{Explanatory note}

Name - the student - in the nominative case

instead of XX introduce the value assessment on a 10-point scale (number only)

Request:

1) The remaining cells do not touch 
2) RC (Reflective card) is filled in for each student individually

\section{Conclusion}

Since professional reflection is an essential component of professionally important qualities of future teachers, practical psychologist in education, at the end of the study of the section, of the module, discipline, a survey of students according to the reflective card will help the teacher and the student to determine the degree of mastery of the course. Compilation of such reflective cards will have some interest among potential employers, if we take into account that they will fill a similar card.

\section{Recommendations}

It is possible to determine the level of student's formation of reflection in other ways. Our method is quite time-consuming, but it is shielded from the subjective assessment. If you have decided to use our proposed reflective card, you must do one of the main conditions: among experts potential employer is desirable.

\section{Acknowledgments}

The work is performed according to the Russian Government Program of Competitive Growth of Kazan Federal University

\section{References}

Bessonova, E. A. (2000). Reflection and its development in the process of training and professional development of future teachers (Dissertation of the candidate of psychological sciences) (p. 160). Khabarovsk.

Biktagirova, G. F., \& Valeeva, R. A. (2013). Technological approach to the reflection development of future engineers. In 2013. International Conference on Interactive Collaborative Learning (p. 427). ICL. http://dx.doi.org/10.1109/ICL.2013.6644615

Biktagirova, G. F., \& Valeeva, R. A. (2014). Development of the teachers' pedagogical reflection. Life Science Journal, $11(9), 60$.

Bizyaeva, A. A. (2004). The psychology of thinking teachers: Pedagogical reflection (p. 216). Pskov: PSU named after S. M .Kirov.

Gabdilkhakov, V. F., \& Kalimullin, A. M. (2014). Tutoring of pedagogical activity and new ideology of teacher training in the higher education institution. Life Sci J., 11(11s), 183-187.

Ganieva, Y. N., Azitova, G. S., Chernova, Y. A., Yakovleva, I. G., Shaidullina, A. R., \& Sadovaya, V. V. (2014). Model of High School Students Professional Education. Life Science Journal, 11(8s), 1097-8135.

Golovin, S. Y. (1998). Dictionary of Practical Psychologist (p. 800). Harvest, Minsk.

Ivanov, V. G., Shaidullina, A. R., Drovnikov, A. S., Yakovlev, S. A., \& Masalimova, A. R. (2015). Regional Experience of Students' Innovative and Entrepreneurial Competence Forming. Review of European Studies, $7(1), 35-40$.

Karpov, A. V. (2003). Reflectivity as a psychic property and method of diagnosis. Psychological journal, 24(5), 45-57.

Levina, E. Y., Yunusova, A. B., Fayzullina, A. R., Rassadin, S. V., Lotfullin, M. R., Nuriyeva, E. N., \& Vlasova, V. K. (2015). Federal Public Administration Implementation in Vocational Education. Review of European Studies, 7(4), 98-104. http://dx.doi.org/10.5539/res.v7n4p98

Lopatina, O. V., Fassakhova, G. R., Akhmetova, L. A., Gatin, R. G., Yarullina, A. S., Nikishina, S. R., \& Khairullina, E. R. (2015). The Technology of Forming the Students' Research Competence in the Process of Learning a Foreign Language. Asian Social Science, 11(3), 152-157.

Markova, A. K. (2005). Formation of learning motivation at school age (p. 246). Moscow: Education.

Masalimova, A. R., \& Nigmatov, Z. G. (2015). Structural-Functional Model for Corporate Training of Specialists in Carrying Out Mentoring. Review of European Studies, 7(4), 39-48. http://dx.doi.org/10.5539/res.v7n4p39

Masalimova, A. R., Schepkina, N. K., Leifa, A. V., Shaidullina, A. R., \& Burdukovskaya, E. A. (2014). Mentoring perfection in modern enterprises conditions: Practical recommendations. American Journal of Applied Sciences, 11(7), 1152-1156. http://dx.doi.org/10.3844/ajassp.2014.1152.1156

Mokeyeva, E. V., Zakirova, V. G., \& Masalimova, A. R. (2015). Tolerant Pedagogic Space as a Condition of Non-Violence Position Education among Elementary School Pupils. Review of European Studies, 7(4), 216-220. http://dx.doi.org/10.5539/res.v7n4p216 
Polivanova, N. I. (2007). Reflection and its role in the process of organizing and structuring of the collective distributed action of children (p. 237). Novosibirsk.

Pyankova, G. S. (2009). The development of professional reflection: A study guide (p. 276). Krasnoyarsk State Pedagogical University named after V. P. Astafev. Krasnoyarsk.

Pyankova, G. S., \& Djukov, V. M. (2010). The role of the reflective-activity pedagogy in the development of effective ways, means and opportunities for the revival of the creative potential of the educational system. Modern high technologies, 10, 103-107.

Romanova, M. V., \& Konstantinov, V. V. (2012). Professional reflection and personal characteristics of students' future educational psychologists. Izv. Penz.gos. pedagog. univ.im.i V. G. Belinskogo, 28, 1330-1333.

Sakhieva, R. G., Khairullina, E. R., Khisamiyeva, L. G., Valeyeva, N. S., Masalimova, A. R., \& Zakirova, V. G. (2015). Designing a Structure of the Modular Competence-Based Curriculum and Technologies for Its Implementation into Higher Vocational Institutions. Asian Social Science, 11(2), 246-251.

Savenkov, I. A., \& Semenov, I. N. (2005). Reflective and psychological aspects of activation of professional self-determination of students - Future psychologists (p. 172). Sochi: REC RAE.

Semenov, I. N. (2009). Reflective Psychology, Acmeology and Pedagogy as means to revive the education system. Ways, means and possibilities of upgrading the educational system. In Proceedings of the conference (pp. 338-348). Moscow: RAE, APSS.

Semenov, I. N. (2011). Reflective consciousness and the intuitive creative act. Psychology questions, 6, 152-155.

Shaidullina, A. R., Fassakhova, G. R., Valeyeva, G. K., Khasanova, G. B., Komelina, V. A., \& Ivanova, T.L. (2015). A Comparative Research on Levels of Students' Formation Skills of Their Career Advancement Portfolio in Secondary and Higher Education Systems. Asian Social Science, 11(1), 375-379.

Shaidullina, A. R., Merzon, E. E., Zakirova, V. G., Mokeyeva, E. V., Karev, B. A., Burdukovskaya, E. A., \& Polevaya, N. M. (2015). The Peculiarities of Perspective Students Selection Mechanism by the Future Employers-Enterprise. Review of European Studies, 7(1), 68-73.

Sibgatova, K. I., Sabirov, I. T., Sadovaya, V. V., Vlasova, V. K., Leyfa, I. I., Yatsevich, L. P., \& Fassakhova, G. R. (2015). Pedagogical potential of the career guidance course "Professional career planning" to form pupils and students' self-determination in the integrated system "school-vocational college". Review of European Studies, 7(1), 80 .

Tukov, A. A. (1995). The mechanism of reflection. In Models of reflection (p. 214). Novosibirsk: Ekor.

Wulfov, B. Z., \& Harkin, V. N. (1995). Pedagogy of reflection (p. 111). Moscow: IChP "Publisher Master".

Zak, A. Z. (1978). Experimental study of reflection of primary schoolchildren. Psychology questions, 2, 102-110.

Zakharova, A .V., \& Botsmanova, M. E. (2006). Features of reflection as a psychic neoformation in training activities (p. 162). Moscow: AST.

Zakharova, A. V. (1993). The Psychology of self-esteem formation (p. 100). Minsk.

\section{Copyrights}

Copyright for this article is retained by the author(s), with first publication rights granted to the journal. This is an open-access article distributed under the terms and conditions of the Creative Commons Attribution license (http://creativecommons.org/licenses/by/3.0/). 